\title{
The digital protection and inheritance of Dunhuang painted sculptures
}

\author{
Xi Zhang a, Shuang Liang \\ School of Art and Design, Lanzhou Jiaotong University, Lanzhou 730070, China \\ a59564008@qq.com
}

Keywords: Painted sculptures of Dunhuang, Digital Protection, Inheritance

\begin{abstract}
Dunhuang painted sculptures is a kind of local characteristics of Intangible Cultural Heritage of Humanity. With exquisite artistic value and the profound cultural value. Due to the artificial destruction and environment, the protection is imminent. This article analyze digital technology in the application of painted sculptures, summarize the advantages and disadvantages, consider that digital protection and inheritance is a new direction and inevitable trend for painted sculptures of Dunhuang.
\end{abstract}

\section{Introduction}

The Mogao grottoes of Dunhuang, also known as the thousand Buddha caves, located in the Hexi corridor, is the 20th century's most valuable cultural discoveries, known as "East's Louvre". As one of the three China Grottoes in Dunhuang Mogao Grottoes with its broad and profound content, art is famous for its exquisite beyond compare. It was listed as the first batch of national key cultural relics protection units in 1961, 1987 was listed by UNESCO as "one of the world's historical and cultural heritage". The one thousand years of construction of Dunhuang grottoes, it is the period of formation and development of Chinese art schools and art theories. After the introduction of Buddhism and Buddhist art, Buddhist art has become an important category of Chinese art. Dunhuang painted sculptures is the main art sculptures of Dunhuang, rich and colorful, colorful theme rich and superb craft, called the painted Buddhist sculpture museum. The true to life of the sculpture and murals vividly shows that thousands of years ago, the ancestors of the religion, art and aesthetic consciousness, also reflected the artisan painters have plastic clever design and craftsmanship. Today, Due to the impact of many natural factors and human factors ,such as environment temperature, humidity, harmful gas and dust, mold and breeding, there is picture spall, crack and color faded change a variety of qualitative phenomenon, let the protection of these treasures is facing serious challenges. However, with the rapid development of modern information technology, the wide application of Internet technology, digital technology as the means and opportunity of collection, preservation, display and communication provides a new Dunhuang colorful intangible cultural heritage. How to use the latest digital information, network technology and virtual reality technology to strengthen the related arts and cultural of forms protection, it is worthy of our attention ${ }^{[1]}$.

\section{The application of digital technology in the the protection and inheritance of Dunhuang painted sculpture}

Digital preservation, restoration, research and development technology will bring the methods and means of cultural relics protection and inheritance to a new stage, and have a very wide application prospect.

\subsection{The application of digital technology in the grottoes environmental monitoring}

The environment in Grottoes, such as temperature, humidity and the concentration of carbon dioxide are the important factors influencing the preservation of sculptures and murals in caves, will directly affect the open to visit the caves. On the one hand, the above parameters are collected by sensors, and all the sensors are made up of a network by using wireless communication technology, so that the data can be transmitted and processed over a long period of time and reliably; On the other 
hand, the active RFID technology and wireless sensor network technology, it can achieve real-time statistics of tourists' flow to the cave. With all kinds of environment real-time digital wireless sensor network monitoring cave changes, so that we can grasp the real-time cave condition, and can according to the situation of the cave environment, timely adjustment or temporary closure of cave strategy, to strengthen the protection of the cave. With all sorts of environmental changes real-time monitored by digital wireless sensor network in caves, we can make the real-time grasp the status of the caves, and can take temporary closed or adjustment strategy timely according to the present situation of environment in caves, in order to strengthen the protection of caves.

\subsection{The application of digital technology in surveying and mapping of archaeological sculptures}

Compared with the traditional manual mapping before, we now through the overlay film and 3D laser scanning technology to obtain relevant data from painted sculptures and murals, and has the characteristics of efficient and accurate. Overlay film is to use mobile digital camera which parallel to the wall, take the grotto murals pictures in turn, then splicing the single digital image into a complete image, and through processing of relevant professional software to ensure the accuracy of the image color and geometric proportion; And 3D laser scanning technology that can help us to get the point cloud, and complete data coordinate system through data registration, and import the point cloud data to Microstation system, According to the geometric characteristics and point cloud intensity data structure and outline the cave statue by line drawing, 3D position determination of mural point cloud data, on the basis of mosaic image outline features of mural images of the line, and in the archaeological map according to the map size picture insert with coordinates data grid for finishing a map, and calculate the accurate position and the actual size of the image. ${ }^{[2]}$

\subsection{The application of digital technology in the database building}

The establishment of the database is an important content of digital protection, the key is to build a database structure, that is what kind of structure could cover painted sculptures in Dunhuang external and potentially important information. The need to build the demand analysis and design of the content and ways of skeleton, so as to establish safety, versatility, scalability, usability, technology and application of combining with the common technology of characteristic database ${ }^{[3]}$. Specifically, on the one hand, using digital technology to organize and classify huge amounts of information about the painted sculptures of Dunhuang including art characteristics, technological process, molding skills such as the collation, classification after the establishment of the database; On the other hand, transforming text, images, sound, video and other data into digital format, and establishing a series of material database, heritage database, etc. The establishment of a multimedia database can improve the efficiency of researchers and conservationists inquire related data, share the resource, expand the space for the protection of the Dunhuang, promote innovative thinking, this way enhance the overall level of study, protection and propagation of Dunhuang painted sculptures.

\subsection{The application of digital technology in the painted sculptures art show}

Today in the unprecedented development of information technology, digital technology was applied to greatly enrich the painted sculptures art show of art display space and means, but also made the Dunhuang art from static to dynamic. Digital museum, the content is the use of 3D animation, virtual roaming and other digital technology around Dunhuang colorful knowledge and scientific interpretation and display, create lifelike, vivid display effect, so that the audience is easy to accept and understand, can soar freely in the colorful world. It has a digital storage of exhibits and a powerful search function, it is possible to mix virtual scene model coordinate display, support environment roaming, details of the product display, a detailed presentation of hand process, etc. while in its future development, we can try to show custom personal museum DIY service, the core membership database query download, remote training, online identification, sales of books and crafts and other cultural projects to achieve sustainable development of digital museum.

\subsection{The application of digital technology in the colorful sculpture art inheriting}

The use of digital technology to promote the painted sculptures art from the following two aspects: First of all, the establishment of network communication platform, On the one hand, it can promote the 
widespread dissemination of painted sculptures of Dunhuang and carry forward the culture of painted sculptures vigorously. On the other hand, it can improve the level of academic research of Dunhuang painted sculptures. Such as: establishing the correlation of colorful murals of Dunhuang site, show the colorful sculpture of Dunhuang works unique charm and artistic achievement, through the propaganda to increase the audience interest and attention of painted sculpture; To promote the exchange and dissemination of the technology of using multimedia technology, there are a lot of folk arts and crafts masters or more representative of the folk artists are invited to the relevant professional colleges or institutes to do lectures, introducing production process of painted sculpture. If they introduce their content and their ideas and design ideas into multimedia courseware, they can help them better communicate with the audience, and promote the spread of folk arts culture. Secondly, 3D printing technology is used to set up DIY experience museum. Audience draw or pattern on embryos which were created in 3D printing, thus the sensation of a production process and unique colorful murals of Dunhuang art, can let the audience to understand and experience the charm of the creation of Dunhuang painted sculptures in a comprehensive way, make sculptures integrate into modern life, cultivate a new batch of painted sculpture lovers.

\section{The advantages of digital technology in protecting and inheriting painted sculptures of Dunhuang}

Digital protection of the Dunhuang painted sculpture is the use of the existing digital technology (such as digital collection, digital storage, digital processing, digital display, digital transmission, etc.), to record, storage and recovery the information of Dunhuang painted sculptures, and establish the database such as text, images, audio, video, animation, to realize digital display.

There are several advantages to protect Painted sculptures of Dunhuang digital protection compared with other traditional way of protection.

\subsection{Accurate}

The development of digital capture and storage technology has provided a guarantee for the complete protection and comprehensive management painted sculptures of Dunhuang. Using digital technology to powerful information processing capacity and processing speed, data acquisition method can achieve any unmatched depth and breadth, to maximum extent, ensures the accuracy of the information retrieval, break through the traditional acquisition methods that cannot meet the accuracy requirement and fidelity effect, for later Dunhuang research work to provide accurate material damage recovery. Such as 3D laser scanning technology applied to the cave of surveying and mapping the measurement speed and accuracy has been greatly improved, using the overlay film technology can obtain high quality, complete murals images, etc. The precision of digital technology is not only reflected in the colorful information, also reflected in the process of its display and transmission. The use of high-precision data acquisition has been, we can build three-dimensional digital model, to achieve Dunhuang colorful visualization, just gently drag the mouse, can achieve different angles and details of the show.

\subsection{Efficient}

Efficiency through in every aspects of painted sculptures of Dunhuang from information collecte, storage, display to heritage. With modern computer graphics, digital image processing and virtual reality, digital technology provides a more advanced means and methods for the inheritance of Dunhuang painted sculptures. Such as using the 2D, 3D digital animation technology, can provide users with a virtual space, recreating the outline of the Dunhuang Mogao grottoes, realize the interactive operation, the sense that gives a person spirit its borders. In addition, people also can share storage device via the Internet or upload the data to a network, breaking the specified time and limited places, in order to achieve a broader Dunhuang painted sculptures cultural exchanges, so that more people know about colorful art and can stimulate the development of national culture vitality; Researchers also can easily access relevant information via search engines, not only to improve the 
research efficiency, but also save the cost-saving research, expanding the protection of ideas, so painted sculptures of Dunhuang can truly become co-owners of the cultural heritage of all mankind.

\subsection{Permanent}

Dunhuang relics protection officers has used the traditional text, recording, photography, video and other means to save a large number of precious material cultural heritage, but as the book of mildew, aging, video tapes, the distortion of the emergence of a series of problems, such as making the preservation of the painted sculptures of Dunhuang data into trouble. And painted sculptures of Dunhuang digital protection by digital information processing, acquisition, establishing database, disk arrays, disc tower, optical fiber and network to set up electronic archives for the intangible cultural heritage ${ }^{[4]}$, breaking through the problems exist in traditional protection way such as damage and distortion in order to maximize compensate the irresistible shortcomings for the human and material outside of natural decay or disappear, saving these precious material culture heritage more real, systematically and comprehensively.

\section{The lacks of digital technology in protecting and inheriting painted sculptures of Dunhuang}

The painted sculptures of Dunhuang is both the witness of historical development, and is a precious cultural resources of great value, its protection is related to cultural national security, social harmony and national culture blood heritage. Therefore, the use of digital technology for the protection and inheritance of Dunhuang painted sculptures is of great significance and is imperative. However, in the process of its protection encounter the problem from all sides inevitably, for example: due to the security problem of digital technology itself, makes the painted sculptures of Dunhuang digital protection under the threaten of the virus; Excessive reliance on digital technology makes digital and inheritance of culture also can damage the cultural diversity and cultural ecological balance to a certain extent, etc., all we need to hand in hand with the technical to the humanities. At the same time, painted sculptures of Dunhuang digital technology brings the knowledge of humanities and social sciences, natural sciences, engineering and technology and other fields together, researchers in all areas need to work together collaboratively to achieve digitization and cultural heritage protection and inheritance of a win-win situation.

\section{Summary}

We are in a new era, in the face of surging tide of western culture, we should actively implement the Chinese digital culture engineering, transform our broad and profound traditional culture resources into digital cultural products, to improve the cultural status of the Chinese civilization in the world, to win strategic initiative in cultural competition.

\section{References}

[1].Dongmei Peng, Lusheng Pan, Shouqian Sun. Digital protection - the new ways of intangible cultural heritage protection. Journal of art research, (2006) No.1, P. 47.

[2].Jinshi Fan. Applied in digital technology to protect the Dunhuang grottoes show. Journal of Dunhuang research, (2009) No.3.

[3].Yongzeng Liu. The painted sculptures of Dunhuang. East China normal university press, 2009.

[4].Yonglin Huang, Guoxin Tan. Digital protection and development of China's intangible cultural heritage research. Journal of central China normal university, (2012) No.3, P. 52. 